\title{
TELEHEALTH FOR FAMILIES OF CHILDREN WITH SPECIAL NEEDS: EXPERTS' OPINIONS
}

\author{
Dincer SARAL \\ ORCID: 0000-0003-0795-255X \\ Hacettepe University \\ Faculty of Education \\ Ankara, TURKEY \\ Dr. Seray OLCAY \\ ORCID: 0000-0002-5007-7466 \\ Hacettepe University \\ Faculty of Education \\ Ankara, TURKEY
}

Received: 16/12/2020 Accepted: 08/04/2021

\begin{abstract}
Telehealth interventions (TI) are broadly defined as the use of information and communication technologies to deliver information, diagnosis, or educational services. While the use of TI was previously just a choice to support children with special needs and their families, they have become a necessity nowadays when performing face-to-face education and training practices are almost impossible. The current qualitative study aims at describing the opinions and recommendations of the experts toward the basic characteristics of TI, guidelines for successful practices, ethical considerations, potential problems, and solutions associated with TI process. Six experts experienced with implementing and conducting research on remote training and coaching participated in the semi-structured interviews that were transcribed and analyzed using content analysis. The analysis revealed four themes: (a) Characteristics of TI, (b) important points in TI, (c) potential problems, and (d) potential solutions. Overall, the findings may shed light on the general conceptual and terminological definition of TI, discussions regarding to feasibility of TI in Turkey, and effective TI practices. Also, the findings may guide future practitioners, researchers, or teachers in conducting or investigating the effectiveness of TI.
\end{abstract}

Keywords: Telehealth, developmental disabilities, family training, expert opinion, remote coaching.

\section{INTRODUCTION}

After the outbreak of Corona Virus in Wuhan, a city in China, in 2019 spread throughout the world in a very short time, the World Health Organization (WHO) declared the emerging situation as a new pandemic in March 11 when it was first seen in Turkey (WHO, 2020). The new COVID-19 pandemic has affected many aspects of daily life, health, and education in particular (Goplani \& Gupta, 2020). In fact, cutting face-to-face education to reduce coronavirus transmission at schools has led to seeking for a new educational model. In Turkey, for example, face-to-face education was stopped on the 26th of March and Ministry of National Education decided to perform courses on an online educational platform, Educational Informatics Network (EBA), and national television channel (i.e., TRT). Moreover, such platforms as Zoom, Google Teams, Hangouts, and Skype were common in delivering educational services during the distance education process (Yilmaz, Mutlu, Guner, Doganay, \& Yilmaz, 2020).

However, problems in accessing educational services arose due to lack of technology such as internet or computers, and education not focusing on individual students' needs (Budak \& Korkmaz, 2020). In other words, distance education did not provide all students with an equal right to access education. Obviously, students with special needs were placed on the top who could not equally benefit from educational services as those with typical development. Benefitting from those services more as long as individualized educational 
programs are implemented in face-to-face, one-to-one or small group instructional format (Tekin-Iftar, 2009), students with special needs have been interrupted in receiving proper educational services during the pandemic (Can, 2020). Thus, in has been inevitable to empower the environment, parents in particular, for these students who have not benefitted from the services sufficiently. Also, the parents of these students have had to play the teachers' role in addition to their own parental roles (Tarbox et al., 2020), which has made family-centered practices much more necessary during the pandemic.

Family-centered practices are implemented by delivering training, consultation or coaching support in natural (e.g., home) or structured settings (e.g., through internet) to the parents to provide their children with more learning opportunities, and to ensure more quality interaction and engagement with them (Reagon $\&$ Higbee, 2009; Wong, 2014). Literature suggests five basic components for the success of family-centered practices as follows (Longo, de Campos, \& Schioriti, 2020): (a) Improving collaboration, (b) setting goals for the child and the parents, (c) employing goal-oriented evidence-based practices and developing home programs, (d) delivering continuous support and coaching to parents, and (e) evaluating the outcomes as a team. These steps clearly highlight the significance of implementing evidence-based practices and of training and coaching for the families of children with special needs. There exists a great number of interventions for the individuals with special needs; however, today's world requires a non-face-to-face practices due to the pandemic one of which is telehealth intervention(s) (TI) (Ferguson, Craig, \& Dounavi, 2019).

Telehealth is broadly defined as the use of information and communication technologies to deliver information, diagnosis or educational services (Nickelson, 1998). TI can be delivered through a wide variety of communication technologies such as telephone, e-mail, or videoconferencing platforms (Phillips, Vesmarovich, Hauber, Wiggers, \& Egner, 2001). Through telehealth, an expert can provide coaching to families that is defined as providing individualized teaching and feedback (Griffiths, 2020). Recent research reveals that a gradually growing interest in the use of TI for the families of children with special needs (Ferguson et al., 2019). In fact, previous research findings on telehealth suggest that most TI included applied behavior analytic procedures for the families of children with autism spectrum disorder (ASD) (Vismara, McCormick, Young, Nadhan, \& Monlux, 2013), and that the families could implement the procedures with high procedural fidelity and stated positive opinions toward the procedure (Salomone et al., 2017) and the children could acquire the skills targeted for them (Boisvert \& Hall, 2014). Also, TI reduce the educational costs by half (Horn et al., 2016), appear to be time-efficient and enable access to wider range of families (Lerman et al., 2020), thus maximizing the efficiency. However, research findings indicate that the success of TI is also dependent on families' access to technological equipment and being trained on how to use them (Lerman et al., 2020).

Although previous research mostly focused on the positive outcomes, limitations, and effectiveness of TI, it appears that there has been a growing interest in investigating the basic components, potential problems, and solutions during TI. For example, Romani and Schieltz (2017) described the ethical issues when delivering TI while Rios, Kazemi and Peterson (2018) provided information regarding to current challenges and recommendations to facilitate the process. In another research by Lerman and colleagues (2020), the experiences and suggestions of 18 practitioners engaging in telehealth on challenges and solutions while providing caregiver training were reported. It can be of high significance to describe the opinions and recommendations of primary experts regarding to TI that appear to be commonly used during the current pandemic context as well as post-pandemic. This information may help teachers, practitioners and researchers effectively design and implement TI process, and guide future research in this emerging area. Therefore, the purpose of the current study is to describe the opinions and recommendations of the experts experienced with implementing and conducting research on remote training and coaching toward the basic characteristics of TI, important points and guidelines for successful practices, ethical considerations, potential problems, and solutions associated with TI process. We think this information can guide the practitioners to design and implement TI effectively, thereby empowering families trained through telehealth practices in supporting their children with special needs. 


\section{METHOD}

\section{Research Design}

The current study employed a qualitative case study research design. One or more cases are described in studies using a case study design (Yildirim $\&$ Simsek, 2016). Thus, the current study aimed at presenting the perspectives of the informants on the case of TI process and analyzing the phenomenon as a whole.

\section{Participants}

The expert participants were identified after ethical consent had been gained from Ethics Committee at Hacettepe University. In identifying the participants criterion sampling, a kind of purposive sampling, was used because we intended to obtain in-depth information regarding to TI (Patton, 2002). Thus, the following inclusion criteria were used to include the participants in the research: (a) working in a special education field, (b) having experience with remote training and coaching, and (c) having conducted or conducting at least one research on remote training and coaching. To identify the participants meeting these criteria, YOKTEZ (National Theses and Dissertations Center), Google Scholar and Web of Science electronic databases were searched using the keywords, aile egitimi, uzaktan egitim, uzaktan kocluk, web tabanli egitim, tele-saglik (in English: parent training, remote training/distance education, remote/distance coaching, web-based training/ education, and telehealth, respectively). Then, the researchers conducting research on remote training and coaching were contacted and asked information regarding to their experience with TI. The experts who conducted one or more studies on TI but did not have any experience with implementation were excluded. Because snowball sampling was also used in the study, the eligible participants were asked whether they could identify any other experts who could meet the inclusion criteria. As a result, a total of six participants volunteered and participated in the study. The demographic characteristics of the participants are presented in Table 1. Participant I also participated in the pilot interview session.

Table 1. Demographic characteristics of the participants

\begin{tabular}{lccc}
\hline & Age & Gender & Experience (years) \\
\hline Participant 1 (P1) & 32 & Female & 8 \\
Participant 2 (P2) & 37 & Female & 14 \\
Participant 3 (P3) & 50 & Female & 29 \\
Participant 4 (P4) & 43 & Female & 20 \\
Participant 5 (P5) & 34 & Male & 11 \\
Participant 6 (P6) & 35 & Female & 10 \\
\hline
\end{tabular}

\section{Data Collection}

In-depth interview data were collected using a semi-structured interview form. Thus, interview questions were developed; however, additional questions were directed to the participants during the interview in accordance with their responses. This flexibility helped the researchers gather more in-depth and richer information regarding to TI (Fylan, 2005).

\section{Semi-structured Interview Form}

Database searches were conducted to determine the questions to be asked during the interviews. Also, interview questions were analyzed in previous research on TI where opinions of practitioners or teachers were described. At that point, authors were e-mailed and asked to share the interview questions that were not reported in the research (e.g., Lerman et al., 2020). Finally, a question pool was generated for the interviews. Then, the relevant questions were chosen in the pool and sent to two experts in special education department for review. According to their views, the interview form that included eight open-ended interview questions were finalized. The form focused on participants' own definition of TI, and opinions toward their usage in 
supporting families of children with special needs, important points, ethical issues and guidelines for ideal telehealth practices, potential problems and solutions associated with telehealth process. Before commencing interviews with the participants, a pilot interview session was conducted with another participant.

\section{Pilot Interview Session}

This session was conducted with a participant who met inclusion criteria for participation. A synchronous online video-conferencing platform was used for the interview that was digitally audiotaped and recorded. The participant interviewed in the pilot interview session was 32-year-old female experienced in special education field for eight years. The session was carried out the time both interviewer (the first author) and the participant agreed upon through a video-conferencing platform to which the participant opted. When the interview was terminated, her opinions were taken toward the suitability of the questions and whether there were any questions to change, add or omit in the form. However, no changes were made in the questions in accordance with her views. Then, the authors together listened to the audio recording and decided that the questions were suitable with the aim of the study, there was no need to change or edit any of the interview questions, and to ask the later interviewees whether they would like to add anything else to their responses regarding to the questions that would not have been asked yet instead of not directing that question.

\section{Interviews}

The volunteer participants who met the inclusion criteria were contacted and offered the mode of participation as well as the interview time options. All participants opted or agreed to conduct the interviews through a video-conferencing platform, Zoom. All interviews were digitally audiotaped and recorded. The participants were informed that the meeting would be audiotaped and recorded, protection of the information would be ensured, and they could withdraw at any time, and their consent was verbally obtained before initiating the interviews.

Table 2. Date, time, and length of the interviews

\begin{tabular}{lccc}
\hline & Date & Time & Length \\
\hline P1 & 20 September 2020 & 15.38 & $30 \mathrm{~m} \mathrm{12s}$ \\
P2 & 23 September 2020 & 12.05 & $22 \mathrm{~m} \mathrm{44s}$ \\
P3 & 01 October 2020 & 21.49 & $33 \mathrm{~m} \mathrm{09s}$ \\
P4 & 04 October 2020 & 18.37 & $21 \mathrm{~m} \mathrm{49s}$ \\
P5 & 05 October 2020 & 14.09 & $44 \mathrm{~m} \mathrm{56s}$ \\
P6 & 07 October 2020 & 10.34 & $32 \mathrm{~m} \mathrm{52s}$ \\
\hline
\end{tabular}

Note. $m=$ minutes, $s=$ seconds

During the interviews, the order of the questions was changed when needed or the question was clarified if the participant could not completely comprehend it, and additional questions were asked to obtain in-depth and richer information. For example, while P2 stated that TI may not work for some children, she was asked the question, "Who exactly do you think TI do not work?". The date, time and length of the interviews were presented in Table 2. The interviews lasted $31 \mathrm{~m}$ and $09 \mathrm{~s}$ in average (Range $=21 \mathrm{~m} 48 \mathrm{~s} .-44 \mathrm{~m} 56 \mathrm{~s}$ ). In the study, as transcriptions were analyzed, a second interview was arranged for P2 and P5 who were asked to further clarify anything they wished or specify where they dis/agreed with the analysis.

\section{Data Analysis}

The data was analyzed using content analysis. Because no change was made after the pilot interview session, the data collected from the participant in that session was also included in data analysis. First, the audio recordings were transcribed in page- and line-numbered Microsoft Word documents and read through by the authors. Second, open coding, creating categories and thematization (abstraction) were carried out during content analysis process (Elo \& Kyngas, 2008). In open coding, codes were given to describe the aspects of 
the content thought to be reflective, and a coding sheet was generated. The transcriptions were read again due to different coding in the coding sheets generated for each participant. After this open coding, categories were freely created, and themes were generated through the concepts that the themes represented (Yildirim \& Simsek, 2016). This process was independently performed by each author. In this process, the authors stated their opinions, discussed, and agreed on the coding in case of any discrepancies. Then, they finalized the coding, categories, and themes. As a result, 15 categories and 4 themes were generated.

\section{Trustworthiness}

In qualitative research, such criteria as credibility, transferability or dependability are used instead of reliability or validity (Yildirim \& Simsek, 2016). For credibility purposes, the interviews in this study were transcribed and the transcriptions were sent to the participants for respondent validation. Next, two participants re-volunteered for the second interview were interviewed for member checking to ensure the validity of the findings. For transferability purposes, study procedure and the stages (e.g., identifying the participants, developing interview questions, interviews, data analysis) were written down in detail, and direct citations were used in reporting the findings. Also, the use of purposeful sampling contributed to transferability. Furthermore, we aimed at strengthening the consistency by validating the transcriptions and ensuring coding consistency. For this purpose, an independent expert who worked as a research assistant in psychological counselling and guidance field and conducted qualitative research after taking lessons on qualitative research methodology listened to all interview audio recordings and confirmed the accuracy of the transcriptions. Also, the expert, as an independent observer, checked each code, category, and theme in the related files that the authors developed upon data analysis. It was planned to come together and examine the content in case of any disagreements. Yet, there were no observed discrepancies.

\section{FINDINGS}

The data obtained from the participants' responses toward telehealth interventions (TI) for families of children with special needs were analyzed in four themes as "characteristics of TI", "important points in TI", "potential problems", and "potential solutions". The themes and categories are presented in Figure 1. Also, we reported the findings by direct citations with participant codes, their page and line numbers. For example, "P6, 2, 57-58" in the citations refers to the participant, page number(s), and line number(s), respectively.

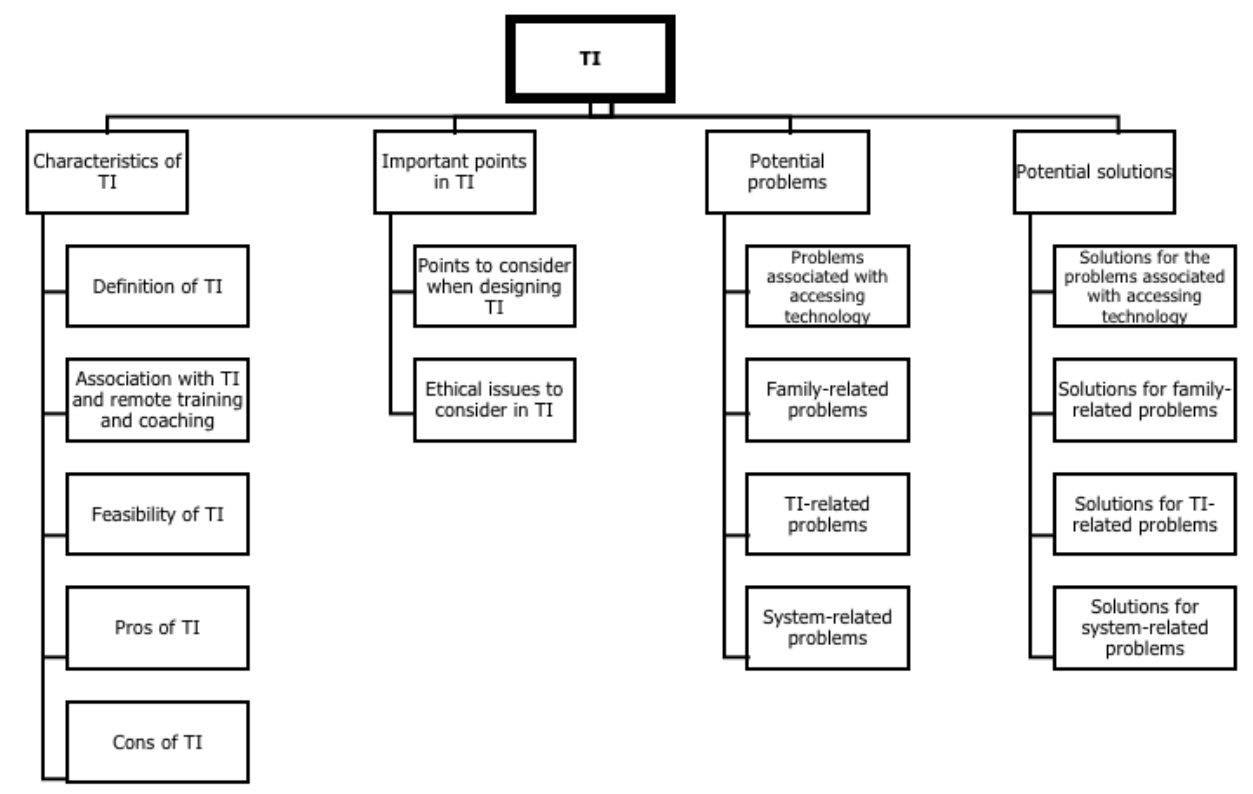

Figure 1. The themes and the categories in the study 


\section{Theme 1: Characteristics of TI}

The data in this theme, characteristics of TI, were analyzed in five categories as definition of TI, association with TI and remote training and coaching, feasibility of TI, pros of TI, and cons of TI. The categories and sub-categories within this theme are presented in Figure 2.

For definition of TI category, four participants defined TI as an interactive and active system that aims to teach information or skills needed by the individuals having difficulty accessing related services. They also mentioned that goal could be achieved through remote training and coaching. In that process, four participants stated online platforms could be used, and one participant different means of communication such as text messages or phone calls: "I would not like to conclude the topic as internet. However, some things could be done through phone calls. Like texting, sending texts... (P5, 3, 104-106)". One participant commented on this issue as "It is a system that aims that families, who cannot access especially experts, can spend home hours, home context, home settings that the expert may not be able to access, or time periods in effective teaching $(\mathrm{P} 2,2$, 62-66)" while another said "In my opinion, it [telehealth] is a health service to provide information... that is provided on internet (P6, 2, 57-58)". Also, two participants said telehealth has been commonly used in the United States of America (USA). One of these participants indicated telehealth as a practice that families in the USA applied for to be able to utilize insurance system: "Telehealth is a system and it is a system based on the economic structure (P3, 3, 123); [telehealth] is a way that families applied for to be able to utilize insurance system (P3, 3, 126)".

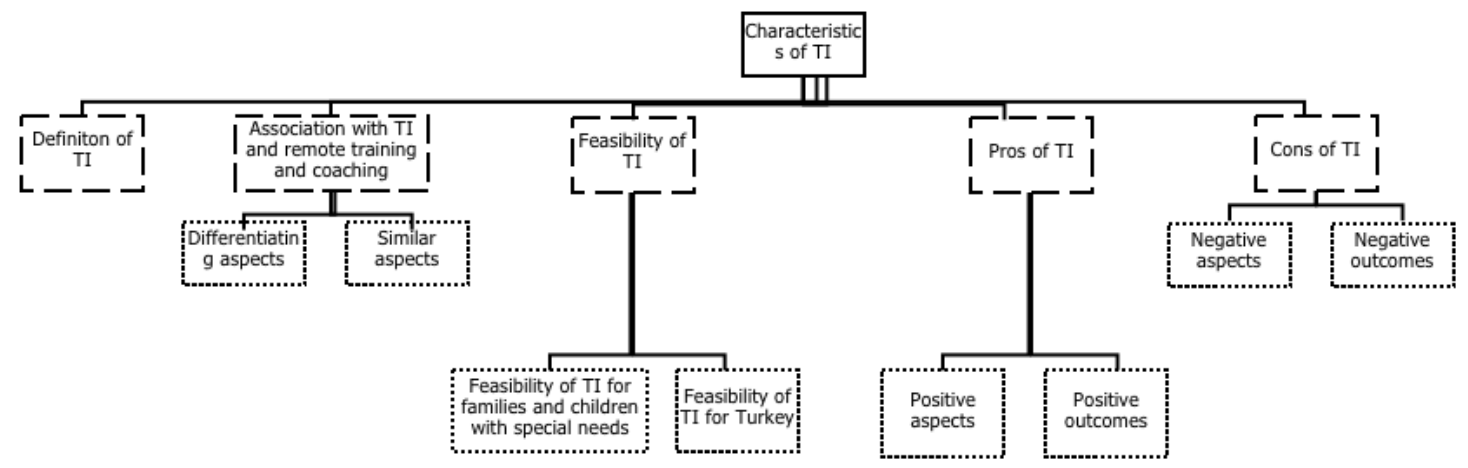

Figure 2. Categories and sub-categories of Theme 1

Association with $T I$ and remote training and coaching category was analyzed within two sub-categories as differentiating aspects and similar aspects. All participants remarked telehealth and remote training and coaching are different from each other. Four participants commenting on differentiating aspects said telehealth was an umbrella term. Two of them focused on differentiating aspects especially on telehealth and coaching and indicated that telehealth was a multidimensional and broad system while coaching was a goal-oriented and limited system as the most differentiating aspect. One participant who conducted research on professional development said "They are not same. There is a system. That system [telehealth] is completely web-based but has multiple dimensions. I mean it is not focused on only one domain like coaching. It is not a limited system to the needs of teachers, students, families or children like professional development practices that we had designed (P2, 2, 58-62)". However, another participant commenting on differentiating aspects noted that coaching was an umbrella term in which telehealth was a means: "Coaching is on the top, but I think we need to assume telehealth is a means in that [coaching] (P3, 3, 117-118)". On the other hand, two participants talking about similar aspects stated that those two - telehealth and remote training and coaching - had similarities, the purposes, and procedures in particular. One participant discussed this as "You may think telehealth does not differ from remote coaching. However, there is a reason why it is called as telehealth. That's what I'm trying to say (P3, 3, 127)". Another said "As a matter of fact, I see them [telehealth and remote training and coaching] similar because both tell us what should be done so that the child can acquire a target behavior or a skill. I also think they are similar in implementation procedures, purposes and rationales (P5, 2, 74-76)". One participant (P6) noted that there are differences between them, and that there is a terminological confusion 
in literature in that researchers still have not arrived at an agreement on this issue.

Participants' opinions toward the feasibility of TI in supporting children with special needs were analyzed under the category of feasibility of TI that included two sub-categories. Five participants commented on feasibility of TI for families and children with special needs and indicated that TI could be a favorable way to support families and children with special needs during pandemic as well as post-pandemic. Also, all participants remarked TI could be an alternative to face-to-face education. The following quotes indicate the examples for that category: "Erm, maybe none of us has experienced such a thing as pandemic before. We definitely should put it [TI] on our agenda... I think it is feasible. It is definitely an alternative to face-to-face education (P2, 2, 69-78)", "It [TI] can be feasible for all time, not just during the pandemic. I mean that the one-on-one practices that I have conducted indicate that remote training has a lot of pluses, especially in education field, for the families having a child with special needs (P4, 2, 51-54)", "My answer, for short-term, would be the pandemic, but we are going to do everything remotely from now on, so we can say we have transitioned into an online era (P1, 2, 63-65)". Another category in that theme is feasibility of TI for Turkey. Three of the participants noted that TI should be examined whether it is feasible for Turkey, so they indicated a need to conduct research on a wide variety of issues such as structure of distance education, resources of families and teachers, and characteristics of coaches: "Is it [TI] effective? So, is it effective in this culture? Does it work? Have we [academics] trained experts who can use that? Have these experts conducted that with high treatment fidelity? Or, can they? Or, have we taught them the skills how to conduct? If we can answer all these questions, then we can answer the question of 'Is it right to use it?', but we have not known that yet (P3, 5, 204-208)".

The category, pros of $T I$, consisted of two sub-categories as positive aspects and positive outcomes. All participants mentioned TI as time-, cost- and transportation-efficient practice: "Transportation, cost. It [TI] reduces both. It enables time flexibility. These are all of its pluses (P4, 3, 97-98)". Moreover, one participant commented TI contributed to social distancing during the pandemic and eliminated physical contact, while another participant mentioned opportunities of developing family-oriented programs and instant responding to families' practices as positive aspects of TI: "When it comes to remoteness, there are more pluses because you can see the parents, their home, and you are inside that home. Right, you are on a screen, but you see everything, and you can provide one-on-one help. You can see their [family's] errors, right practices and you have the chance to intervene in instantly (P4, 2, 55-60)." In the sub-category of positive outcomes, participants' opinions were analyzed within TI's positive outcomes for family, family psychology and child development. Participants' opinions for this sub-category were related to parents' teaching skills to their children [e.g., "If educated right, parents can implement evidence-based practices (P3, 6, 231)"], parents' recognizing to contribute to their children's development [e.g., "Don't we start believing in that we are able to be successful as we achieve things? Thus, TI has shown that families can perform positive things for their children (P5, 6, 220-224)"], parents' recognizing that their children acquire lots of skills [e.g., "[There had existed] a pessimism related to what their children could not do and in which they [parents] thought their children could not do that, could not do this... or [there had existed] an over-acceptance. I think it [TI] had positive impacts on these issues (P5, 6, 229-232)"]. One participant discussed that TI reduced family stress, enhanced parent-child interaction quality, improved family motivation, and reduced family's desperateness, thus helping them see the future more positively with the following quotes: "That [TI] has effects even on family stress, and on their expectations from the future. I mean mother-child or father-child will be spending more functional time together (P2, 4, 135-137)", and "I mean they [families] can minimize that desperateness they have, thus seeing the future more positively [thanks to TI] (P2, 4, 151-153)". Three of the participants indicated positive outcomes of TI as allowing facilitated learning and supporting the skills that could not be taught at school: "For example, some skills cannot be taught at school. They definitely should be learned at home settings. Because parents, now, notice that children are able to acquire them (P5, 3-4, 129-132)".

The category of cons of TI consisted of two sub-categories as negative aspects and negative outcomes. Four participants mentioned positive aspects of TI. Two of them noted that TI required continuous interaction between the expert and family, while three stated TI was not suitable for every child, family or skill: "Above all, it [TI] may not be as effective as face-to-face format for all children or families (P2, 3, 92-93)" and "Sometimes we cannot win, control, make eye-contract with the child during tabletop teaching. There are some times when we cannot perform even we [practitioner and child] are side-by-side or have difficulty. Maybe doing such thing [giving education] may create a few problems for our children, our group (P1, 5, 178-184)". Further, only one 
participant mentioned that families could not maintain the skills they acquired through TI as negative outcomes: "They talk about remote coaching, but families do not maintain implementing what they have acquired when the coaching is terminated (P3, 6, 234-236)".

\section{Theme 2: Important Points in TI}

The theme, important points in TI, was analyzed in two separate categories as points to consider when designing TI and ethical issues to consider in TI. The categories and sub-categories within this theme are presented in Figure 3.

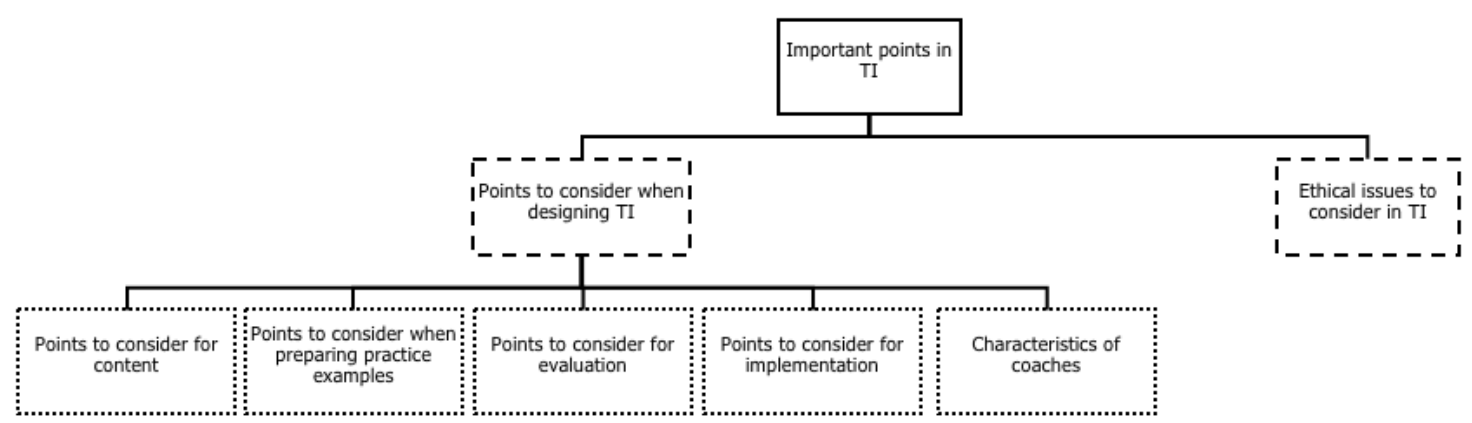

Figure 3. Categories and sub-categories of Theme 2

Regarding to the points to consider for content sub-category, all participants remarked that the content should be determined considering the needs of families so that TI could be effective: "Here "person-specific and situation-specific' things must be regarded. I mean we prepare individualized education programs considering the student. So, TI must include that individualization (P5, 6, 236-239)."

Four participants talked about points to consider when preparing practice examples, and suggested preparing true video examples as well as false examples all of which was recorded using a model with special needs instead of a typically developing model: "Erm, [there should be] video examples with a child with special needs recorded in a non-manipulated natural setting in which each implementation steps are clearly seen, and that even depicts how we [practitioners] effectively deal with problem behaviors or learning opportunities as we do in our daily teaching sessions, and that especially includes false examples, which allows additional learning (P2, 4-5, 173 181 )". Only one participant mentioned including self-evaluation system into the process might improve the effectiveness of TI, which is analyzed within the sub-category of points to consider for evaluation: "If we teach them how they can evaluate themselves... I mean if we include it [self-evaluation] in the process, we can not only disseminate it, but also utilize the resources more efficiently (P2, 5, 189-191)".

All participant stated opinions toward the points to consider for implementation and remarked providing families with feedback regarding to their practices and that the feedback must be given continuously and frequently. Two participants indicated that presenting the content in a short time using written, visual or auditory materials would facilitate the effectiveness of the practices: "Erm, only info text or reading material may not be sufficient. I mean it [TI] should be supported by adding visual and auditory materials (P6, 4, 135137)".

Finally, all participants indicated that characteristics of coaches play a significant key role in the effectiveness of TI, thus suggested including coaches with specific qualifications when designing a TI. They noted the characteristics of coaches as follows: (a) experienced with teaching methods, remote training, knowing about and communicating with families, and assessment, (b) professional and technologic competence, (c) being supportive, open to self-development, explorer, motivating, respectful, leader, cooperative, accessible, empathetic, flexible, and being able to give supportive feedback. The following quote indicates some characteristics of a coach: 
"Empathy. Being able to show empathy toward the family. They [coaches] definitely should have such a characteristic and can effectively communicate with families (P4, 5, 194-195)."

"I think these are the two things that a coach must have: The language helshe uses and maybe being accessible all the time (P2, 5-6, 212-213)."

"'You did it right.', 'Here, it is wonderful what you've just did.', 'Now, you need to do these.' Therefore, I can say having a positive point of view (P3, 7, 288-290)."

"I think his/her [coach's] personality traits should include being motivative and supportive (P6, 4, 175-176)."

Regarding to the category of ethical issues to consider in $T I$, all participants pointed out the principle of confidentiality as the basic ethical issue to consider. One participant remarked "Such practices get us to have much data for sure. There are videos or photos. So, I think it is the responsibility of the coach to protect these and not to use them for any other purposes. Nobody else should reach them (P5, 8, 312-315)." This principle was followed by being constructive in that three participants indicated that the practitioners of TI should be constructive: "First, we [practitioners] focus on accurate behaviors, on what they [families] could do. Erm, starting from constructive and reinforcing feedback is the most ethical dimension (P2, 6, 219-220)." In addition, participants commented on being respectful [e.g., "I mean the first thing to come to the mind is respect when we think of ethics (P5, 8, 303)"], improving personal and professional development [e.g., "It is his/her [coach's] responsibility to follow evidence-based practices and to pursue professional development (P3, 8, 308-309)"], giving consultation about the subjects that the coaches are competent in [e.g., "So, helshe [coach] needs to perform practices within what helshe is competent in (P3, 8, 311-314)"], and taking action in case of a neglect or an abuse [e.g., "Also, properly reporting such things as neglect or abuse or so on occurring at home (P3, 7, 297-298)"].

\section{Theme 3: Potential Problems}

The data in this theme, potential problems, were analyzed in four categories as problems associated with accessing technology, family-related problems, TI-related problems, and system-related problems. The categories within this theme are presented in Figure 4.

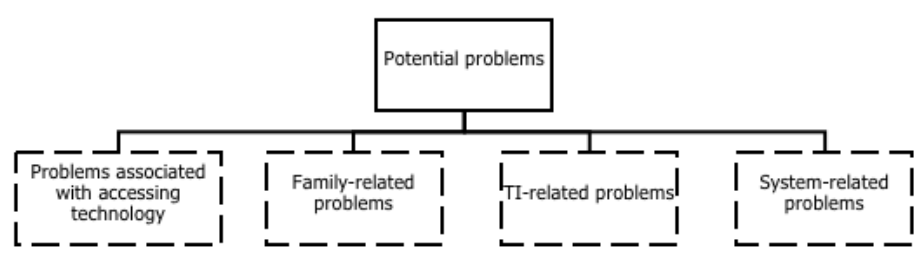

Figure 4. Categories and sub-categories of Theme 3

All participants commenting on problems associated with accessing technology talked about the problems resulting from families' and practitioners' not having internet and sufficient equipment (i.e., computer, microphone), and lack of knowledge on how to use technology: "[TI] requires technical infrastructure for sure. We can assume it ranges from internet speed to technical equipment. It requires families have them and access them. Also, as a service provide, the practitioner is required to have a technical infrastructure such as continuous connection and so on. These are the issues where problems may arise (P6, 6, 248-254)."

As to family-related problems, the data were analyzed within families' negative attitudes toward TI, not allocating enough time, being too time-flexible, being too protective of their children, assuming their privacy would not be protected, and discontinuing TI thinking they could not progress enough. Participants pointed out families' negative attitudes toward TI by remarking "What I would like to say here is attitude. I mean the person should believe... [The person should] believe that some things could be achieved through this [TI] (P5, 4, 180-181)." Also, the participants commented on families' being not allocating enough time: "I mean the 
families may wish to get service but may also say they don't have time (P6, 7, 261-262)." Further, the participants mentioned families' protective roles: "Families have a problem that is being too protective of their children. That should be changed (P2, 6, 250-251)." Moreover, the following quotes points at participants' opinion toward families' assuming their privacy could not be protected: "I mean the families may have troubles about that special conditions regarding to their children are shared online, on internet (P6, 6, 221-223).", and toward discontinuing TI thinking families could not progress enough "Although the family... not the child... Although the family progressed so much, they wanted a practitioner who could come to their house due to the assumption that they could not progress as much as they expected (P5, 5, 175-176)."

As to TI-related problems, the data were analyzed within the problems of implementation of TI and of qualifications of practitioners. One participant talked about problems due to remoteness: "However remote it [TI] is, it requires an emotional gesture, mimic, or social interaction. So, we may not see all of these in TI as we do in genuine communication (P5, 9, 356-359).", while another mentioned problems in assessment procedure in TI: "I mean the problem about how you will assess the parent and the child (P4, 5, 164-165)." On the other hand, the participants also discussed about the problems that may result from the qualifications of practitioners on implementing TI: "Also, the professional development of the person who performs that practice and getting himselflherself competent. These fields [TI] are continuously developing (P3, 8, 322-324)."

Lastly, only one participant talked about the problems that may result from lack of structure, human resources, and research shedding light on implementing the system in Turkey. Thus, the participant mentioned systemrelated problems: "So, how can TI work in Turkey? Do we have enough number of coaches for TI? (P3, 4, 134136).”

\section{Theme 4: Potential Solutions}

Participants' opinions toward potential solutions for the potential problems were analyzed in this theme. The categories within this theme are presented in Figure 5.

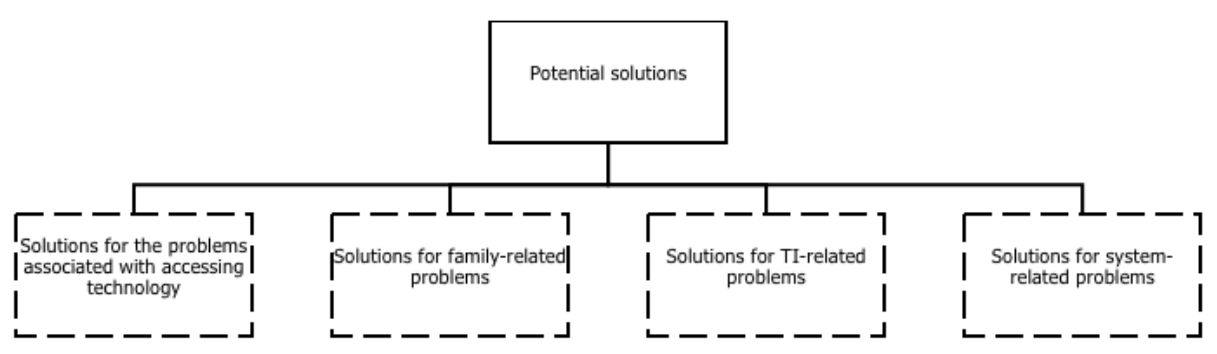

Figure 5. Categories and sub-categories of Theme 4

Regarding to solutions for the problems associated with accessing technology, the participants talked about solutions as providing families and practitioners with technologic infrastructure and equipment, and supporting families in how to use technology: "If the countries spend their resources appropriately in accordance with social justice and if a system is developed based upon supporting the poor, then these are not the problems that cannot be solved especially by Turkey (P3, 9, 336-338)." "[There can be] resources that help families benefit from technology, which aims to improve the knowledge and skills of them - especially families of children with special needs. There can be trainings, brochures on that [P2, 7, 266-268).", and "If there will be distance education especially during the pandemic as well as post-pandemic, then this process can be organized by meeting beforehand when trainings can be performed [on how to use technology]. I mean this can be planned as a separate training, as a family training series. I think there should be some things toward planning distance education, toward what Zoom is or how it is used, for the families of children with special needs (P1, 6, 201-208)."

Participants mentioned, in the category of solutions for family-related problems, solutions for improving family attitudes toward TI: "We need to show the family how important it [TI] is and how the child has progressed. Then, they really take it seriously (P4, 6, 238-240)." Also, the participants provided solutions for the problems related to time: "You know, exclusive rights have been given to those who have such children [with 
special needs]. For example, for some jobs they can take one day off once a week now. So, they can spend that day with their children, or they can get permission during specific hours... I don't know, maybe a babysitter support can be provided to them (P5, 11, 436-443)." The following quote indicates an opinion of a participant toward solutions for families' assuming their privacy would not be protected: "They can be reassured that data of their children will be private and will not be shared with anybody. I mean... Maybe... A contract can be signed... (P6, 7, 286-288)." Possible solutions stated by the participants for discontinuing TI thinking families could not progress enough are also noted: "I mean if families do something good for their children, [believe that] they can be a good teacher or effectively touch lives of the children as much as a teacher does... Actually, they can be the best teachers ever. They know every characteristic of their children. If [a practitioner] succeeds in making the families trust in themselves... (P2, 7, 274-278)."

One participant noted that, in the category of solutions for TI-related problems, providing TI through different ways apart from internet would prevent internet-related problems: "There are families living in rural who do not access internet for sure, but here we don't only refer to internet by saying TI. You can make phone calls, send SMS. Or maybe because sending voice recordings is also a TI, we need to think about the whole (P5, 9-10, 384,388)." One participant suggested solutions for the problems that may result from practitioners' limited qualifications: "It is strongly important that we diversify undergraduate programs, I mean in terms of courses, and to train [students] with specific qualifications (P3, 8, 325-328)."

Only one participant commented on solutions for system-related problems: "Covid period well taught us that we need to raise awareness among undergraduate programs, our students, preservice teachers, and behavior analyst candidates. See many faculty members in the USA are conducting research on How to Teach Online, writing books, working on how they can teach children with special needs remotely. So, what have we done? Only one mobile application has been developed in Turkey by Ministry of National Education. I haven't seen anything, but that application. I mean we really should have been discussing these by now (P3, 8, 322-325)."

\section{DISCUSSIONS AND CONCLUSION}

The current study described the opinions and recommendations of the experts experienced with implementing and conducting research on remote training and coaching toward the TI for families. Their responses toward TI for families of children with special needs were analyzed in four themes as "characteristics of TI", "important points in TI", "potential problems", and "potential solutions". This section discusses the findings within each theme and provides directions for future research.

\section{Characteristics of $\mathrm{TI}$}

One of the themes developed in the study is "characteristics of TI". One of the categories in which most comments were stated within this theme is the definition of TI. The participants defined TI as an interactive and active system that is delivered to individuals having difficulty in accessing related services to teach them knowledge and skills through remote training and coaching. Although the participants remarked TI was delivered through remote training and coaching, they stated both concepts were different. In fact, four participants indicated telehealth was a wider concept than remote training and coaching, whereas one participant vice versa. Further, one participant noted that there was a conceptual confusion in literature. In literature, telehealth, in contrast to tele-medicine used for diagnosis or treatment, is defined as an umbrella term consisting of such practices as behavioral health, consultation and education training (Knutsen et al., 2016; Machalicek et al., 2016). Thus, telehealth can be regarded as a service delivery model for implementing remote training and coaching. However, it is notable that authors in previous research used different terms such as telehealth-supported coaching (Benson et al., 2018), telehealth coaching (Little, Dunn, Pope, \& Wallisch, 2016; Young, Ward, \& Tang-Feldman, 2014), or telehealth program (Alfurayda, Croxall, Hurt, Kerr, \& Brophy, 2020). Also, the terms - telehealth, and remote training and coaching were used synonymously (Kizir, 2019) or as different concepts (e.g., Wainer \& Ingersoll, 2015) in previous research. This suggests that there is still a confusion and inconsistency regarding to the use and definition of these terms, so further research is required to establish the basic similarities and differences between the terms. Participants indicated that TI was an appropriate way to support the children with special needs 
and their families both during and after the exceptional circumstances. Considering the recent arguments of transitioning into a hybrid system in education (Ertan-Kantos, 2020), the present findings seem to be consistent with those of the recent research. Furthermore, three participants suggested that feasibility of TI for Turkey should be tested and mentioned a need for further research on this. Literature suggests that the feasibility of TI is questionable especially for developing countries due to a wide variety of reasons such as broadband connection, higher cost of hardware, and lack of practitioners (Kareem \& Bajwa, 2011). This is consistent with the recommendations of the participants in this study upon the need of research investigating the feasibility of TI in Turkey. Feasibility of a practice should be determined according to its effectiveness as well as "cost-efficiency", "satisfaction", "compatibility with local values", and "easiness to use" (Fawcett, 1991). Thus, future research conducted in various geographical regions in Turkey is warranted to investigate the feasibility and acceptability - social validity -, compatibility with education system and culture, consumer satisfaction, cost-efficiency of TI, and when and whom for TI can be employed instead of face-to-face format. Findings on participants' opinions indicated that they mentioned pros more than the cons of TI that were requirement of continuous interaction with the family, families' not maintaining the acquired skills, and unsuitability of TI in every child, family, and skill. These findings on negative aspects of TI are consistent with those in previous research, which advances the literature (Bilmez, 2020; Iacono et al., 2016; Yang et al., 2020). These findings also indicate a need for future investigations on which characteristics the children, families and skills should have so that TI can be effective, under which circumstances TI can work (e.g., face-to-face pre-training prior to TI), and what should be done to maintain the acquired skills by the children or families. Finally, future studies may focus on describing expert opinions toward which children, families and skills TI may be suitable, and what adaptations should be performed for the children with various characteristics (e.g., duration of the meeting).

\section{Important Points in TI}

The participants indicated a wide variety of points to consider, which will improve the effectiveness of TI, such as family-oriented content, true as well as false video examples, using videos including participants with special needs, continuous feedback for families, and inclusion of qualified coaches in TI. Iocano and colleagues (2016) state that volunteering as well as qualification of the practitioner are significant so that TI can be successful. Moreover, video examples for the families (Meadan et al., 2016), continuous feedback for families and family- and child-oriented target skills (Simacek, Elmquist, Dimian, \& Reichle, 2020) play crucial roles in designing TI, which is consistent with the findings in our study. Thus, future research may compare the effectiveness and efficacy between two TI procedures in which true and/or false examples are used. Moreover, future research can investigate the effectiveness of TI in which families can perform self-feedback through checklists and can explore perceptions on the expected qualifications of a coach. In addition, the relevance and effectiveness of such components as homework, quizzes, multiple-choice assessment questions, forums, and diaries on the level treatment fidelity coefficient are also important issues for future research.

Participants' opinions about ethical issues regarding to confidentiality, constructive and respectful characteristics of the practitioners, maintenance of professional and personal development, and consultation within competent fields seem to be consistent with the ethical guidelines and codes of some organizations such as Behavior Analyst Certification Board (e.g., BACB 2.06 - Maintaining Confidentiality) and American Psychological Association. In addition, this finding is consistent with the checklist of ethical issues to comply during TI developed by Baumes, Colic and Araiba (2020). Thus, future researchers should use this recent emerging checklist and use platforms compliant with Health Insurance Portability and Accountability Act (HIPPA) (e.g., Zoom, GoToMeeting) that requires sensitive data protection so that potential and undesirable ethical results of TI would not arise. 


\section{Potential Problems}

Participants discussed problems associated with accessing technology, family, TI, and the system. In one study by Lerman and colleagues (2020), experiences and opinions of 18 practitioners who provided families with remote training and coaching were described. The authors reported most frequent challenges as technical issues (e.g., no access to equipment), challenges with remote viewing (e.g., difficulty to see or hear), disruptions in environment (e.g., interruption of sessions by family members), issues related to client's behavior (e.g., engaging in undesired behaviors), issues related to caregiver's behavior (e.g., emotional responding), and issues related to the practitioner (e.g., not being specifically trained for TI). In the current study, all participants not only mentioned same issues and challenges reported by that study, but also indicated system-related problems resulting from negative attitudes of families toward TI and lack of practitioners and infrastructure in Turkey. In fact, negative family attitudes may be unique to Turkey in that families are too protective of their children (Canatan, Konbak, Aslan, Ozdemir, \& Yilmaz, 2020) and they are not familiar with remote training (Ak, Sahin, Cicekler, \& Ergun, 2020). Further studies with more focus on examining these problems and challenges to improve effectiveness, efficacy and social validity of TI are therefore suggested. Also, future studies, which explore the opinions of service receivers (i.e., families) as well as service providers on potential problems during TI, will need to be undertaken.

\section{Potential Solutions}

The recommendations of the participants experienced with implementing and conducting research on remote training and coaching for the solutions of potential problems may guide future researchers and practitioners in this emerging field, TI. These findings on potential solutions are not only consistent with those of Lerman et al. (2020) that described recommendations of service providers for challenges during TI, but also produced additional solutions for those unique to Turkey. In fact, the participants recommended improving family attitudes for discontinuation of TI, the use of various ways apart from internet for TI-related problems and performing awareness raising for system-related problems. Thus, some recommendations for the solutions seem to require short- and some long-term planning. For example, practitioners may establish a lending library for families and provide them with the equipment (e.g., microphone). On the other hand, long-term planning may include developing positive attitude among families toward TI, facilitating active participation, and training qualified practitioners. Thus, it is recommended that practitioners use data-based decisions and inform the family of children's progress, support families through corrective and constructive feedback, and hold the meetings in the way they do not negatively affect family participation (e.g., not interrupting family routine or using family preferred means of communication). There would, moreover, seem to be a definite need for developing effective educational models in training qualified practitioners and training practitioners in undergraduate programs who are qualified with remote training and coaching and comply with ethical issues. Thus, elective, or/and compulsory courses on remote training, remote coaching and telehealth can be commenced in Special Education departments at universities. Also, some parts of teaching practice/internship courses can be conducted remotely to improve preservice teacher's related skills.

The current study described the opinions of the experts experienced with implementation and research on TI in terms of various dimensions, and accordingly discussed precautions for feasibility and acceptability of TI for Turkey. The study explored the opinions of six participants eligible for the study, so it is limited to the opinions of them. Also, this can be regarded as a limitation for the literature on remote training and coaching. Although we used document analysis in identifying the participants, the data were collected only through conducting interviews with them. However, it is thought that this study provides significant contributions to Turkish literature in that it can shed light on future studies and researchers upon a newly developing and emerging area, TI.

Acknowledgements: We thank all the experts who were part of this study for giving their consent and cooperation with the interviews. 


\section{BIODATA and CONTACT ADDRESSES of AUTHORS}

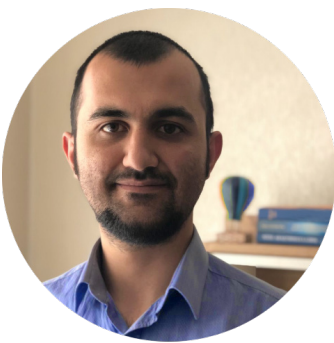

Born in Hatay in 1990, Dincer SARAL graduated from the Department of English Language Teaching, Anadolu University in 2012. He received his master's degree in Applied Behavior Analysis for Autism at Anadolu University with his thesis on "Teaching Pretend Play Skills to Children with Autism Spectrum Disorder" in 2017. Then, he started PhD program at the Department of Special Education at the same university. He is one of the founding members of Association of Applied Behavior Analysis (UDADER) in Turkey that aims to support the growth of applied behavior analysis. Saral has been working as a research assistant at Special Education department at Hacettepe University. His primary line of inquiry focuses on teaching individuals with intellectual disabilities and autism spectrum disorder, applied behavior analysis, evidence-based practices and play skills.

Dincer SARAL

Department of Special Education, Faculty of Education

Address: Hacettepe University, Faculty of Education, Special Education Department, 06800, Beytepe Campus, Cankaya, Ankara, TURKEY

Phone: +903122976315

E-mail: dincersaral@hacettepe.edu.tr

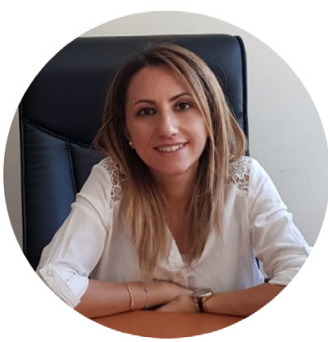

Born in Ankara in 1982, Seray OLCAY graduated from Department of Psychology, Ankara University in 2004. She started Joint PhD program at the Department of Special Education at Anadolu University in 2005. She worked as a psychologist or a manager at various special education and rehabilitation centers while in the doctoral program. She has had researcher, educator, expert, and scholar roles on various projects: UNICEF, European Union, Scientific Research, TUBITAK, Ministry of Family, Labour and Social Services, and received her PhD in 2012. She conducted research as a visiting scholar at the University of North Carolina, Charlotte for six months in 2016. She received her associate's degree in 2018. Dr. Olcay's continuing interests are on teaching individuals with intellectual disabilities and autism spectrum disorder, applied behavior analysis, parent consultation and training, and single-subject research methodology. She has been in the Special Education department at Hacettepe University since 2015. There are many numbers of published papers of hers in various journals worldwide, and presentations at different congresses.

\section{Seray OLCAY}

Department of Special Education, Faculty of Education

Address: Hacettepe University, Faculty of Education, Special Education Department,

06800, Beytepe Campus, Cankaya, Ankara, TURKEY

Phone: +903122976315

E-mail: serayolcaygul@hacettepe.edu.tr

\section{REFERENCES}

Ak, M., Sahin, L., Cicekler, A. N., \& Erturk, M. A. Kovid-19 Kuresel salgin surecinde Istanbul Universitesi uzaktan egitim uygulamalarina genel bir bakis. Istanbul Universitesi Sosyoloji Dergisi, 40(2), 1-42. doi: 10.26650/SJ.2020.40.2.0076

Alfuraydan, M., Croxall, J., Hurt, L., Kerr, M., \& Brophy, S. (2020). Use of telehealth for facilitating the diagnostic assessment of autism spectrum disorder (ASD): A scoping review. PloS one, 15(7), 1-16. doi: 10.1371/journal.pone.0236415

Baumes, A., Colic, M., \& Araiba, S. (2020). Comparison of telehealth-related ethics and guidelines and a checklist for ethical decision making in the midst of the covid-19 pandemic. Behavior analysis in practice, 13(4), 736-747. doi: 10.1007/s40617-020-00475-2 
Benson, S. S., Dimian, A. F., Elmquist, M., Simacek, J., McComas, J. J., \& Symons, F. J. (2018). Coaching parents to assess and treat self-injurious behaviour via telehealth. Journal of Intellectual Disability Research, 62(12), 1114-1123. doi: 10.1111/jir.12456

Bilmez, H. (2020). Gelisimsel yetersizligi olan cocuklarin ebeveynlerine sunulan kocluk uygulamalarinin ebeveynlerin ogretim becerileri ve cocuklarinin iletisim becerileri uzerindeki etkileri [The effects of coaching on teaching skills of parents and communication skills of their children with autism spectrum disorder.] (Doctoral dissertation). Anadolu University Graduate School of Social Sciences, Eskisehir, Turkey. Available from the Council of Higher Education, National Theses and Dissertation Center, Dissertation ID: 646438.

Boisvert, M., \& Hall, N. (2014). The use of telehealth in early autism training for parents: a scoping review. Smart Homecare Technology and Telehealth, 2, 19-27. doi: 10.2147/SHTT.S45353

Budak, F., \& Korkmaz, S. (2020). COVID-19 pandemi surecine yonelik genel bir degerlendirme: Turkiye ornegi. Sosyal Arastirmalar ve Yonetim Dergisi, (1), 62-79. doi: 10.35375/sayod.738657

Can, H. B. (2020). Olaganustu durumlarda gelistirilen sosyal politikalarin dezavantajli gruplar uzerindeki etkisinin sosyal hizmet perspektifinden degerlendirilmesi: Covid-19 pandemisi Turkiye ornegi. Sosyal Hizmet, 47-63.

Canatan, K. (2020). Geleneksel ve modern ailelerde cocuk yetistirme tutumlari. Istanbul Sabahattin Zaim Universitesi Sosyal Bilimler Dergisi, 8(16), 151-165.

Elo, S., \& Kyngas, H. (2008). The qualitative content analysis process. Journal of Advanced Nursing, 62(1), 107-115. doi: 10.1111/j.1365-2648.2007.04569.x

Ertan-Kantos, Z. (2020). Sinif ogretmenlerinin uzaktan egitim ile ilgili dusunceleri. In K. Ciftyildiz (Ed.), the $8^{\text {th }}$ International Scientific Research Congress (UBAK), 2020 (pp. 67-81). Hattusa: Asos Press.

Fawcett, S. B. (1991). Social validity: a note on methodology. Journal of Applied Behavior Analysis, 24(2), 235. doi: 10.1901/jaba.1991.24-235

Ferguson, J., Craig, E. A., \& Dounavi, K. (2019). Telehealth as a model for providing behaviour analytic interventions to individuals with autism spectrum disorder: A systematic review. Journal of autism and developmental disorders, 49(2), 582-616. doi: 10.1007/s10803-018-3724-5

Fylan, F. (2005). Semi-structured interviewing. J. Miles ve P. Gilbert (Eds.), In $A$ handbook of research methods for clinical and health psychology (s. 65-78), New York: Oxford University Press.

Goplani, M., \& Gupta, A. (2020). Impact of coronavirus 2019 on educational institutions in India. The Online Journal of Distance Education and e-Learning, 8(3), 158. doi: 10.13140/RG.2.2.32141.36321

Griffiths, F. (2020). The Effects of Telehealth Training on Parents of Children with Autism in Albania. Brigham Young Ubiersity, Utah. (Master's Thesis). Available from Brigham Young University Scholars Archive, ID: 8427.

Horn BP, Barragan GN, Fore C, Bonham CA. A cost comparison of travel models and behavioural telemedicine for rural, Native American populations in New Mexico. Journal of Telemedicine and Telecare, 22(1), 47-55. doi: 10.1177/1357633X15587171

Iacono, T., Dissanayake, C., Trembath, D., Hudry, K., Erickson, S., \& Spong, J. (2016). Family and practitioner perspectives on telehealth for services to young children with autism. Stud Health Technol Inform, 231, 63-73. doi: 10.3233/978-1-61499-712-2-63

Kareem, S. \& Bajwa, I. S. (2011). A virtual telehealth framework: Applications and technical considerations. $7^{\text {th }}$ International Conference on Emerging Technologies (ICET), 2011 (pp. 1-17). Islamabad: Piscataway Press. doi: 10.1109/ICET.2011.6048445

Kizir, M. (2019). Reviewing of telehealth (distance) coaching practices for autism spectrum disorder. Cukurova University Faculty of Education Journal, 48(2), 1072-1110. doi: 10.14812/cufej.569720

Knutsen, J., Wolfe, A., Burke, B. L., Hepburn, S., Lindgren, S., \& Coury, D. (2016). A systematic review of telemedicine in autism spectrum disorders. Review Journal of Autism and Developmental Disorders, 3(4), 330-344. doi: 10.1007/s40489-016-0086-9 
Lerman, D. C., O’Brien, M. J., Neely, L., Call, N. A., Tsami, L., Schieltz, K. M., ... \& Cooper-Brown, L. J. (2020). Remote coaching of caregivers via telehealth: Challenges and potential solutions. Journal of Behavioral Education, 29(2), 195-221. doi: 10.1007/s10864-020-09378-2

Little, L., Dunn, W., Pope, E., \& Wallisch, A. (2016). Feasibility of a telehealth coaching intervention for families of children with autism. American Journal of Occupational Therapy, 70(4_ Supplement_1):7011515244p1-7011515244p1.doi: 10.5014/ajot.2016.70S1-PO1059

Longo, E., deCampos,A.C., \&Schiariti,V.(2020).COVID-19 pandemic: isthisagood timeforimplementation of home programs for children's rehabilitation in low- and middle-income countries? Physical and Occupational Therapy in Pediatrics, 40(4). doi: 10.1080/01942638.2020.1759947

Machalicek, W., Lequia, J., Pinkelman, S., Knowles, C., Raulston, T., Davis, T., \& Alresheed, F. (2016). Behavioral telehealth consultation with families of children with autism spectrum disorder. Behavioral Interventions, 31(3), 223-250. doi: 10.1002/bin.1450

Meadan, H., Snodgrass, M. R., Meyer, L. E., Fisher, K. W., Chung, M. Y., \& Halle, J. W. (2016). Internetbased parent-implemented intervention for young children with autism: A pilot study. Journal of Early Intervention, 38(1), 3-23. doi: 10.1177/1053815116630327

Nickelson, D. W. (1998). Telehealth and the evolving health care system: Strategic opportunities for professional psychology. Professional Psychology: Research and Practice, 29(6), 527. doi: $10.1037 / 0735-7028.29 .6 .527$

Patton, M. (2002). Qualitative Research and Evaluation Methods. London: Sage Publications.

Phillips, V. L., Vesmarovich, S., Hauber, R., Wiggers, E., \& Egner, A. (2016). Telehealth: reaching out to newly injured spinal cord patients. Public Health Reports, 116(1), 94-102. doi: 10.1093/phr/116. S1.94

Reagon, K. A., \& Higbee, T. S. (2009). Parent-implemented script fading to promote play-based verbal initiations in children with autism. Journal of Applied Behavior Analysis, 42(3), 659-664. doi: 10.1901/jaba.2009.42-659

Rios, D., Kazemi, E., \& Peterson, S. M. (2018). Best practices and considerations for effective service provision via remote technology. Behavior Analysis: Research and Practice, 18(3), 277. doi: 10.1037/ bar0000072

Romani, P. W., \& Schieltz, K. M. (2017). Ethical considerations when delivering behavior analytic services for problem behavior via telehealth. Behavior Analysis: Research and Practice, 17(4), 312-324. doi: $10.1037 /$ bar0000074

Salomone, E., \& Maurizio Arduino, G. (2017). Parental attitudes to a telehealth parent coaching intervention for autism spectrum disorder. Journal of Telemedicine and Telecare, 23(3), 416-420. doi: $10.1177 / 1357633 X 16642067$

Simacek, J., Elmquist, M., Dimian, A. F., \& Reichle, J. (2020). Current trends in telehealth applications to deliver social communication interventions for young children with or at risk for autism spectrum disorder. Current Developmental Disorders Reports. Advance online publication. doi: 10.1007/ s40474-020-00214-w

Tarbox, C. M., Silverman, E. A., Chastain, A. N., Little, A., Bermudez, T. L., \& Tarbox, J. (2020). Taking action: 18 simple strategies for supporting children with autism during the covid-19 pandemic. Behavior Analysis in Practice. Advance online publication. doi: 10.1007/s40617-02000448-5

Tekin Iftar, E. (2009). Sistematik ogretim. E. Tekin Iftar, (Ed.), In Davranis ve ogrenme sorunu olan cocuklarin egitimi (pp. 63-82), Eskisehir: Anadolu Universitesi Press.

Vismara, L. A., McCormick, C., Young, G. S., Nadhan, A., \& Monlux, K. (2013). Preliminary findings of a telehealth approach to parent training in autism. Journal of Autism and Developmental Disorders, 43(12), 2953-2969. doi: 10.1007/s10803-013-1841-8 
Wainer, A. L., \& Ingersoll, B. R. (2015). Increasing access to an ASD imitation intervention via a telehealth parent training program. Journal of autism and developmental disorders, 45(12), 3877-3890. doi: $10.1007 / \mathrm{s} 10803-014-2186-7$

World Health Organization. Coronavirus disease (COVID-19) pandemic. Geneva: WHO; 2020.

Wong, O. L. (2014). Contextual barriers to the successful implementation of family-centered practice in mental health care: A Hong Kong study. Archives of Psychiatric Nursing, 28(3), 212-219. doi: 10.1016/j.apnu.2014.02.001

Yang, H. W., Burke, M., Isaacs, S., Rios, K., Schraml-Block, K., Aleman-Tovar, J., ... \& Swartz, R. (2020). Family perspectives toward using telehealth in early intervention. Journal of Developmental and Physical Disabilities. Advance online publication doi: 10.1007/s10882-020-09744-y.

Yildirim, A., \& Simsek, H. (2013). Sosyal bilimlerde nitel arastirma yontemleri. Ankara: Seckin Yayincilik.

Yilmaz, E., Mutlu, H., \& Doganay, G. (2020). Veli algisina gore pandemi donemi uzaktan egitim surecinin niteligi. Konya: Palet Press.

Young, H., Miyamoto, S., Ward, D., Dharmar, M., Tang-Feldman, Y., \& Berglund, L. (2014). Sustained effects of a nurse coaching intervention via telehealth to improve health behavior change in diabetes. Telemedicine and e-Health, 20(9), 828-834. doi: 10.1089/tmj.2013.0326. 